\title{
Worry and perceived risk of contagion during the COVID-19 quarantine in the Jalisco population: Preliminary Study
}

\author{
Jesua Iván Guzmán-González, ${ }^{1,2}$ Franco Giordano Sánchez-García, ${ }^{2}$ Saúl Ramírez-de los Santos, ${ }^{3}$ \\ Francisco Gutiérrez-Rodríguez, ${ }^{1}$ David Palomino-Esparza ${ }^{4}$ Ana Laura Telles-Martínez ${ }^{5}$
}

Centro de Evaluación e Investigación en Psicología, Departamento de Psicología Básica, Centro Universitario de Ciencias de la Salud, Universidad de Guadalajara, Guadalajara, Jalisco, México.

2 División Profesional de Innovación y Desarrollo Tecnológico en Psicología, Colegio de Profesionales de la Psicología del Estado de Jalisco CPPJAC, Guadalajara, Jalisco, México.

3 Centro de Atención Médica Integral, Centro Universitario de los Altos, Universidad de Guadalajara, Jalisco, México.

${ }^{4}$ División Profesional de Psicología de las Emergencias, Colegio de Profesionales de la Psicología del Estado de Jalisco CPPJAC, Guadalajara, Jalisco, México.

5 Sociedad de Egresados de la Licenciatura en Psicología de la Universidad de Guadalajara, Guadalajara, Jalisco, México.

Correspondence:

esua Iván Guzmán-González Centro Universitario de Ciencias de la Salud, Facultad de Psicología, Departamento de Psicología Básica. Sierra Nevada 950, edificio H planta alta, Col. Independencia 44340, Guadalajara, Jalisco, México. Phone: 33 2388-3081

Email: jesua.guzman@alumnos.udg.mx

Received: 12 April 2020

Accepted: 29 June 2020

Citation:

Guzmán-González, J. I., SánchezGarcía, F. G., Ramírez-de los Santos S. Gutierrez-Rodríguez, F., Palomino-Esparza, D. \& \& Telles-Martínez, A L. (2020). Worry and perceived risk of contagion during the COVID-19 quarantine in the Jalisco population: Preliminary Study. Salud Mental, 43(6), 253-260

DOI: $10.17711 /$ SM.0185-3325.2020.035

\begin{abstract}
Introduction. Preventive measures taken during periods of health crisis, specifically in pandemics, have consistently been associated with detrimental effects on mental health. Isolation and loneliness are indirect effects of these preventive measures. Given these premises, monitoring the behavior of the population in the face of these eventualities becomes important. Worry as an indirect measure of anxiety and stress enables one to recognize subjects who are vulnerable to phenomena of high uncertainty, since measures taken to avoid excessive contagion can have high costs for this population. This phenomenon has been consistently observed in other pandemics such as $\mathrm{H} 1 / \mathrm{N} 1$ influenza. Objective. To determine the prevalence of worry and perceived risk of contagion in the Guadalajara population during the COVID-19 quarantine and to identify differentiating effects. Method. A total of 255 people from western Mexico (Guadalajara, Jalisco) voluntarily participated by answering the Penn State Worry Questionnaire (PSWQ) adapted to Mexican population. The average age of the respondents, aged between 18 and 70 years, was 31.71 ( \pm 5.19$)$. A total of 170 women and 85 men participated in the study. Results. $40.12 \%$ of the population scored high levels of worry, making them vulnerable to mental health conditions. Subjects favored the prevention of a contagion regardless of whether they were self-isolated. The only variable that had a differential effect was sex $(p<.05)$, and there were no differences in educational attainment, occupational demandingness, and isolation between the groups. Discussion and conclusion. A preventive attitude was observed among the participants, and so it is important to implement strategies that will prevent mental health costs in those who express excessive worry to avoid saturating mental health services.
\end{abstract}

Keywords: Pandemic, COVID, psychosocial risk, worry, anxiety.

\section{RESUMEN}

Introducción. Las medidas preventivas tomadas durante periodos de crisis de salud, específicamente en las pandemias, se han asociado constantemente a efectos perjudiciales en la salud mental. El aislamiento y la soledad son efectos indirectos de estas medidas preventivas. Dadas estas premisas, monitorear la conducta de la población ante estas eventualidades cobra importancia. La preocupación como medida indirecta de la ansiedad y el estrés puede permitir reconocer aquellos sujetos que se encuentren en una situación de vulnerabilidad ante fenómenos de alta incertidumbre, por lo que las medidas tomadas para evitar contagios excesivos pueden tener un costo alto para dicha población. Este fenómeno se ha observado consistentemente en otras pandemias como la de la influenza H1/N1. Objetivo. Determinar la prevalencia de preocupación y riesgo de contagio percibido en población tapatía durante la cuarentena por COVID-19 e identificar efectos diferenciadores. Método. Un total de 255 personas del occidente de México (Guadalajara, Jalisco) participaron voluntariamente contestando el Cuestionario de Preocupación del Pensilvania (PWSQ) adaptado a la población mexicana. La edad promedio fue de 31.71 ( \pm 5.19 ) de entre los 18 y los 70 años. Un total de 170 mujeres y 85 hombres participaron en la encuesta. Resultados. El $40.12 \%$ de la población alcanzó puntajes altos de preocupación, que los vuelven vulnerables a los padecimientos de salud mental. Se expresaron datos favorables en pro de la prevención de un contagio independientemente de si se estaba en situación de aislamiento o no. Por otro lado, la única variable que tuvo un efecto diferencial fue la del sexo $(p<.05)$, mientras que la escolaridad, la exigencia ocupacional y el aislamiento no mostraron diferencias entre grupos. Discusión y conclusión. Se observa una actitud de prevención en los participantes; es importante realizar estrategias que eviten que haya costes a razón de la salud mental en aquellos que muestra preocupación excesiva para evitar la saturación de los servicios de salud mental.

Palabras clave: Pandemia, COVID-19, riesgo psicosocial, preocupación, ansiedad. 


\section{INTRODUCTION}

Health systems worldwide keep radical protocols and strategies for emerging and reemerging diseases. These rigid measures can counteract epidemics and pandemics among the population, protecting physical health, especially in vulnerable people. One of these measures is quarantine, which involves separating and restricting the movement of people who have potentially been exposed to a contagious disease, thereby reducing the risk of infecting others. This definition differs from isolation, which involves separating people who have been diagnosed with the disease (Brooks et al., 2020).

At present, a new coronavirus, called severe acute respiratory syndrome coronavirus 2 (SARS-CoV-2), has infected the human population and a pandemic has developed that has altered the psycho-socioeconomic fabric of the world population. This virus has caused a large number of deaths and tens of thousands of confirmed cases worldwide, posing a serious threat to physical and mental public health (Li, Liu, Yu, Tang, \& Tang, 2020).

A virus with a pandemic potential must be exhaustively monitored to prevent both direct and indirect clinical and epidemiological manifestations (de Jong, Claas, Osterhaus, Webster, \& Lim, 1997), which is the basis for building first-line plans for its containment and, if possible, eradication (Kuri-Morales, Betancourt-Cravioto, Velázquez-Monroy, Alvarez-Lucas, \& Tapia-Conyer, 2006). A pandemic has direct effects on health, due to its effects on the functioning of the organism, and indirect effects, such as the attitudes, perceptions, and psychological distress caused in a population (Perrin, McCabe, Everly, \& Links, 2009), and in some cases secondary effects have greater repercussions on social functioning than primary ones (Cheng \& Cheung, 2005), since this forces the population to undergo emergency isolation to avoid future risky infections. In response to this outbreak, quarantine has been implemented in Mexico, as well as in other countries, as a measure to prevent and control the pandemic. The population most susceptible to severe cases are the elderly and people with underlying diseases or low immune function and pregnant women, while infected newborns are prone to developing severe pneumonia (Li et al., 2020). The costs of epidemics and pandemics, as well as the measures implemented, such as quarantine, not only encompass economic and cultural issues, but also negative psychological effects such as post-traumatic stress symptoms, confusion and anger, as well as fear of infection, frustration, boredom inadequate supplies, inadequate information, financial losses, and stigma. Some studies suggest that these effects can be long-lasting (Brooks et al., 2020).

The idea that social isolation is extremely dangerous for mental health is not necessarily new, with findings clarifying the magnitude of its effect on other populations, both pathological and healthy (Andersson, 1998). They also demonstrate that isolation and/or loneliness have more detrimental effects on mental health service users than the general population (Lauder, Sharkey, \& Mummery, 2004). In previous studies, a relationship between the feeling of isolation and loneliness (I\&L) and the presence of anxiety (Caplan, 2007) and suicidal behavior (Goldsmith, Pellmar, Kleinman, \& Bunney, 2002) has been demonstrated. Interventions to lessen the detrimental effects of I\&L have had a strong impact on the population suffering from it (Windle, Francis, \& Coomber, 2011), especially in reducing worry and uncertainty levels (Butler, 2006).

Worry is essentially the core of anxiety, as this is a sequence of anxious thoughts with a highly emotional content usually directed towards the future (Kelly \& Miller, 1999), which, in turn, are prone to appear during I\&L (Flett, Goldstein, Pechenkov, Nepon, \& Wekerle, 2016). Although they are a phenomenon commonly experienced on a day-to-day basis, worry is a concept associated with stress and anxiety (Hirsch \& Mathews, 2012), although they are not synonymous in phenomenological terms (Davey, 1993). Previous studies have reported that approximately $72 \%$ of people experience severe worry at least once a month (Tallis, Davey, \& Capuzzo, 1994). However, pathological worry is a risk factor during pandemics. This type of worry is perceived as excessive and uncontrollable for the person experiencing it (Davey, 1994).

Therefore, due to the recent outbreak of COVID-19, which had its epicenter in China and has spread globally (Dong \& Bouey, 2020), certain forms of mental health care have been developed that seek to prevent harmful effects due to the constant worry about infection, uncertainty and isolation (Jiang et al., 2020; Liang, Mays, \& Hwang, 2017). And as has been the case with other pandemics such as H1/ $\mathrm{N} 1$, stronger anxiety outbreaks will occur during phases two and three that will significantly decline during the last phase (Bults et al., 2011) since it is a natural response to pandemics, as has been observed in previous experiences (Wheaton, Abramowitz, Berman, Fabricant, \& Olatunji, 2012). Knowing, relatively accurately, the effects on mental health due to I\&L (Taha, Matheson, Cronin, \& Anisman, 2014) and monitoring the perceptions and behavioral responses of the general public enables us to obtain useful information for future measures in response to pandemics (Taylor et al., 2009). This has been the case in previous years. A series of studies on risk perception and responses in the case of 2009 influenza were published, which enabled the development of preventive measures for the population (Seale et al., 2010).

Overestimation of both the positive and negative consequences of excessive, uncontrollable worry is one of the characteristics of Generalized Anxiety Disorder and other mood disorders (González, Bethencourt, Fumero, \& Fernández, 2006). This variable and its related aspects 
have been evaluated through various instruments, such as the following: Why worry?, the Intolerance of Uncertainty Scale (IUS) (Freeston, Rhéaume, Letarte, Dugas, \& Ladouceur, 1994), the White Bear Suppression Inventory (WBSI) (Wegner \& Zanakos, 1994), The Problem Solving Inventory-Revised (Maydeu-Olivares \& D'Zurilla, 1995), Beck's Anxiety Inventory (BAI) (Beck, Epstein, Brown, \& Steer, 1988), the Structured Interview Guide for the Hamilton Anxiety Scale (SIGH-A) (Shear et al., 2001), the Penn State Worry Questionnaire (PSWQ) (Meyer, Miller, Metzger, \& Borkovec, 1990), and so on. All the above instruments are reliable and valid and have been used in various populations for studies on worry.

The latter is an instrument validated in Mexican population that is ideal for the evaluation of pathological worry, as well as being useful in clinical contexts. Studies have analyzed the psychometric properties of the Penn State Worry Questionnaire (PSWQ) in its Spanish versions: the original scale (PSWQ-16) (Meyer et al., 1990), the direct form of the scale PSWQ-16D (Ruiz Díaz, Montorio Cerrato, \& Nuevo Benítez, 2002), and two abbreviated versions PSWQ-11 (Sandín, Chorot, Valiente, \& Lostao, 2009) and PSWQ-8. In this regard, it has been determined that the original scale (PSWQ-16) is built according to a model of two related factors, in contrast to the analysis of the PSWQ-16D, PSWQ-11, and PSWQ-8 versions built under a single factor (one-dimensional). In all cases, high internal consistency and test-retest reliability and adequate concurrent and discriminant validity were identified (Padrós-Blázquez, González-Betanzos, Martínez-Medina, \& Wagner-Echeagaray, 2018).

Regarding the assessment of perceived exposure, vulnerability, and risk of contagion to diseases, there are several instruments designed for specific clinical contexts, such as HIV infection (Bayés, Pastells, \& Tuldrá, 1995), avian influenza (Fielding et al., 2005), and so on. Also in the context of alarming public health situations, research has been conducted on perceived vulnerability to influenza A (H1N1), in which four main dimensions were identified: catastrophic power, threat, control, and knowledge of participants (Aragonés, Talayero, \& Olivos, 2010). The scale of perceived vulnerability to the disease has also been used (Magallares, Fuster-Ruiz De Apodaca, \& Morales, 2017) in the SARS-CoV-2 contingency (González-Olmo, Ortega-Martínez, Delgado-Ramos, Romero-Maroto, \& Carrillo-Diaz, 2020), which includes two subscales: perceived infectivity and germ aversion, both with acceptable internal consistency measured by Cronbach's alpha.

In this regard, it is important to mention that both evaluation of pathological worry in the general population and the perceived risk of contagion in extreme epidemiological situations such as the one we are currently experiencing as a result of COVID-19, is crucial for identifying indicators of vulnerability to psychopathology and exposure to risk situ- ations among the general population. Although the PSWQ16 and PSWQ-11 questionnaires have already been used in Mexican population samples (Padrós-Blázquez et al., 2018), even in patients in the clinical context (Velázquez Díaz, Espinoza González, Martínez Medina, \& Padrós Blázquez, 2016), and also in relation to generalized anxiety disorder (Starcevic, 1995), neither the prevalence nor the association between pathological worry and perceived risk of SARS-CoV-2 in Jalisco have been established. This study therefore has various objectives, the first one being to determine the prevalence of worry in a Guadalajara population during the COVID-19 quarantine. The second objective was to construct and implement an instrument to measure the perceived risk of contagion. The last objective was to identify variables with a differentiating effect in worry in the population under study.

\section{METHOD}

\section{Participants}

A convenience sampling was carried out of people who were close to the mental health services of the College of Psychology Professionals in the state of Jalisco and social networks of the University of Guadalajara, who wished to participate voluntarily. A total of 255 subjects from western Mexico (Guadalajara, Jalisco) participated voluntarily. The average age of subjects between 18 and 70 years was $31.71( \pm 5.19)$, who answered the Penn State Worry Questionnaire (PWSQ) adapted to Mexican population by Padrós-Blázquez et al. (2018). The distribution by sex was $33.33 \%$ (85) men and $66.67 \%$ (170) women. In addition, they were asked about the number of days they had been self-isolated, regardless of whether this had been voluntary or obligatory. Of the total sample, $81.5 \%$ had been self-isolated for between five and 10 days, while the remaining $18.5 \%$ answered it when they had done so for 10 to 25 days.

\section{Measurements}

Of the instruments validated for Mexican population, the PSWQ-16 was used in its Spanish version with 16 5-level Likert-type items where 1 is scored as nothing and 5 as very much. Eleven items are direct and five are inverse (1, 3, 8,10 , and 11) and evaluate the general tendency to worry or worry-trait, which appears to play an important role in generalized anxiety disorder. The scale has an alpha of .917, $\mathrm{X}^{2}=404.23, \mathrm{gl}=104, p<.001, \mathrm{CFI}=.91$, TLI $=.90$, and RMSEA $(90 \% \mathrm{CI})=.06[.05, .08]$, which seems to indicate a reliable, stable instrument for the evaluation of the construct (Padrós-Blázquez et al., 2018). To determine the participants' state of worry, a calculation was made through 
Table 1

Intervals used for categorizing worry in the Mexican population

\begin{tabular}{lc}
\hline Category & Interval \\
\hline Lack of worry & $<20$ \\
Low worry & $20-30$ \\
Normal & $31-51$ \\
High worry & $52-62$ \\
Alarm & $>63$ \\
\hline
\end{tabular}

Note: The calculation was made by adding and substracting the \pm 1 and \pm 2 standard deviations to make the intervals.

standardization where the mean and standard deviations of the expected scores were obtained $(41.70 \pm 10.97)$. The intervals used are shown in Table 1.

\section{Procedure}

The questionnaire was applied individually from March 22 to April 3, 2020 by filling in the scale on a table or computer. Data were stored virtually to be analyzed later. At the time of application, instructions were given verbally and in writing. Subjects read and accepted the informed consent before answering the scale, and were informed that the study adhered to the ethical code established by the Official Mexican Norm regarding research with human beings (NOM-012-SSA3-2012), and it was also specified that the data obtained would only be used for research purposes and that the privacy and identity of the participants would be protected. The average time they took to answer the questionnaire was 4:03" ( $\pm 2: 32 ")$ minutes.

\section{Statistical analyses}

Statistical tests were performed in Software R version 3.6.3 (R Core Team, 2020). For the treatment of data, the Kolmogorov-Smirnov normality test was submitted, obtaining scores that confirm a non-parametric treatment of the data $(p<.05)$. Data that were treated in a non-parametric way were tested with a Mann Whitney's U test to determine whether there were differences by group for the total PSWQ score. Additionally, when the data allowed, Cohen's d (d) was calculated for the effect size and derived from the latter, the overlap index (OVL), which enables us to know the percentage of intersection observations have in scores.

\section{Ethical considerations}

The Project was approved (SELPUDGA00421320) by the Ethics Committee of the Society of Graduates of the Degree in Psychology A.C., and was developed according to institutional ethical standars and those established by the Declaration of Helsinki. All participants signed informed con- sent which safeguards the voluntary and free participation of the participants in the study. In addition, it ensured the follow-up of the participants identified with high concern and taking care of anonymity.

\section{RESULTS}

Figure 1 shows the categories into which the sample to be studied was distributed, with $58.6 \%$ of participants obtaining scores within expectations $(44.69 \pm 4.75)$. The remaining $30.6 \%$ scored high levels of worry $(56.39 \pm 2.94)$ with only $10.6 \%$ obtaining scores reflecting alarm $(67.48 \pm 4.10)$. Within these, $50.59 \%$ answered that they were self-isolating although $49.41 \%$ said they were not. Attempts were made to determine whether there was a differential effect between the groups that were in total isolation and the PSWQ scores where no significance was obtained (Table 2).

Table 3 shows the answers to questions on contagion measures, attitudes, and behaviors towards COVID-19. The questions that were answered were: Have you had contact with someone with symptoms? (Primary contact), Do you think that you observe the hygiene rules properly? (Hygiene), Do you think any of your nuclear relatives (parents and/or siblings) has symptoms? (Nuclear family contagion), Do you think that any of your extended relatives (cousins, uncles and/or grandparents) has symptoms? (Contagion extended family), Do you think that any of your nuclear contacts (close friends and/or partner) has symp-

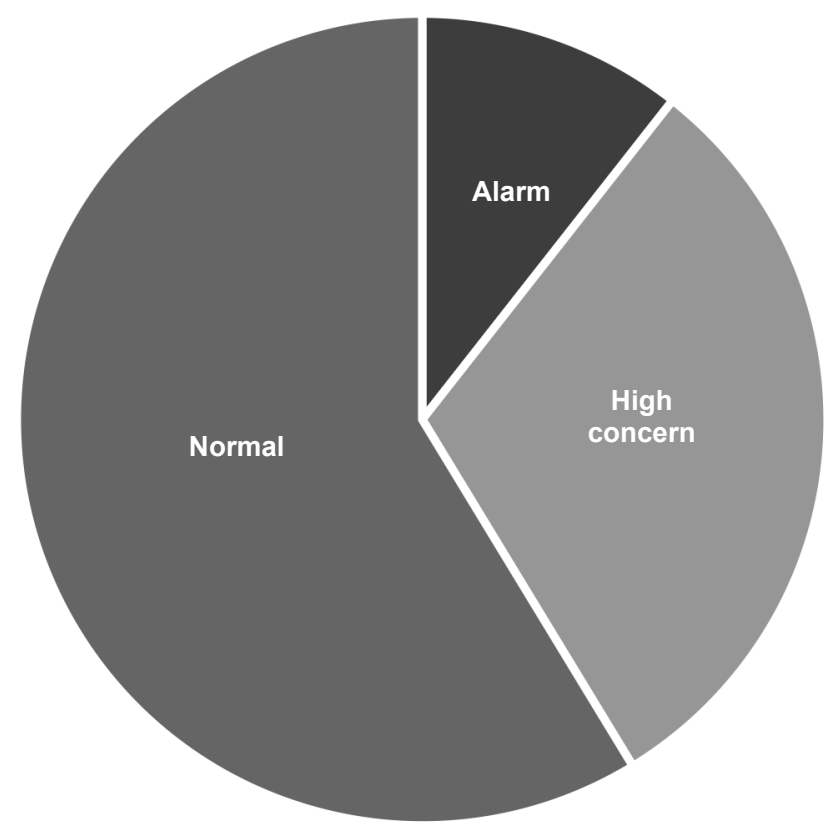

Figure 1. Distribution by categories of scores obtained on the PSWQ in Guadalajara, Jalisco. 
Table 2

Differences in PSWQ in groups by sex, educational attainment, and occupational demandingness

\begin{tabular}{lcccccc}
\hline Variables & \multicolumn{2}{c}{$P S W Q$} & $U$ & $p$ & $d$ & OVL \\
\hline Sex & Woman & Man & & & & \\
& $52.32 \pm 9.15$ & $47.40 \pm 7.30$ & 9455.5 & $.001^{*}$ & .60 & .76 \\
Occupational demandingness & Low & Hlgh & & & & \\
& $49.53 \pm 8.50$ & $51.23 \pm 9.02$ & 7768.5 & .210 & .19 & .92 \\
Educational attainment & $\mathrm{HE}$ & Graduate & & & & \\
& $48.88 \pm 8.01$ & $50.26 \pm 7.68$ & 900 & .673 & .18 & .92 \\
Isolation & Yes & No & & & & \\
& $51.48 \pm 9.05$ & $49.87 \pm 8.65$ & 7120 & .087 & .18 & .92 \\
\hline
\end{tabular}

Notes: $\mathrm{U}=$ Mann Whitney's $\mathrm{U} ; p=$ Significance; $\mathrm{d}$ = size effect; $\mathrm{OVL}=$ Cohen's $\mathrm{d}$ overlap coefficient; $\mathrm{HE}=$ higher education; ${ }^{*} p<.01$.

toms? (Contagion in nuclear relations), Do you think any of your extended contacts (neighbors, acquaintances, fre-

Table 3

Sample's answers to questions about contagion measures, behaviors adopted and isolation due to suspected COVID-19 in Jalisco

\begin{tabular}{|c|c|c|}
\hline \multirow[b]{2}{*}{ Variables } & \multicolumn{2}{|c|}{ Isolation } \\
\hline & No & Yes \\
\hline \multicolumn{3}{|c|}{ Primary contact } \\
\hline Perhaps & - & - \\
\hline No & 120 & 125 \\
\hline Yes & 6 & 4 \\
\hline \multicolumn{3}{|l|}{ Hygiene } \\
\hline Perhaps & 47 & 37 \\
\hline No & 5 & 1 \\
\hline Yes & 74 & 91 \\
\hline \multicolumn{3}{|c|}{ Nuclear family contagion } \\
\hline Perhaps & 5 & 7 \\
\hline No & 120 & 119 \\
\hline Yes & 1 & 3 \\
\hline \multicolumn{3}{|c|}{ Extended family contagion } \\
\hline Perhaps & 10 & 12 \\
\hline No & 111 & 115 \\
\hline Yes & 5 & 2 \\
\hline \multicolumn{3}{|c|}{ Nuclear relatives contagion } \\
\hline Perhaps & 12 & 20 \\
\hline No & 107 & 102 \\
\hline Yes & 7 & 7 \\
\hline \multicolumn{3}{|c|}{ Extended relatives contagion } \\
\hline Perhaps & 27 & 26 \\
\hline No & 91 & 11 \\
\hline Yes & 8 & 92 \\
\hline \multicolumn{3}{|l|}{ Impact } \\
\hline Perhaps & 26 & 19 \\
\hline No & 8 & 10 \\
\hline Yes & 92 & 200 \\
\hline
\end{tabular}

quent friends) has symptoms? (Contagion in extended relationships), and Do you consider that your actions have a significant impact on preventing the spread of COVID-19? (Impact).

Given that the best way to determine the probability of being infected is based on contact and isolation, scores were given to the questions asked in the questionnaire, and determined as follows: Isolation (Yes [0], No [1], Maybe [.5]), Primary contact (Yes [1], No [0], Maybe [.5]), Hygiene (Yes [0], No [1], Maybe [.5]), Contagion nuclear family (Yes [1], No [0], Maybe [.5]), Contagion extended family (Yes [1], No [0], Maybe [.5]), Contagion nuclear relatives (Yes [1], No [0], Maybe [.5]), Contagion extended relatives (Yes [1], No [0], Maybe [.5]), Impact (Yes [1], No [0], Maybe [.5]). The total sum was obtained directly in such a way that the

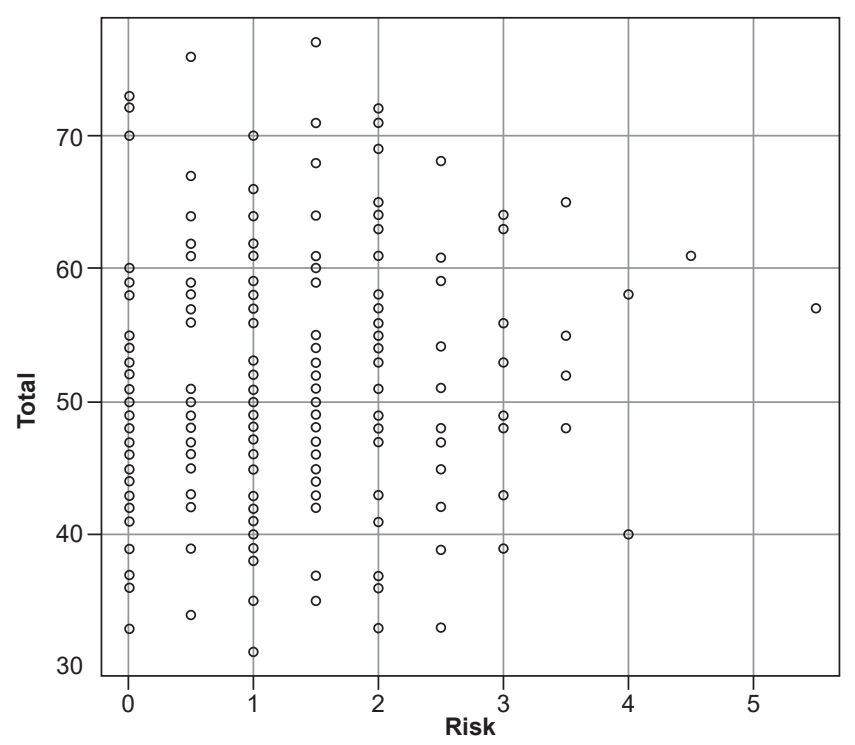

Figure 2. Scatter graph of total score of scale and score obtained from risk due to contact in Jalisco population. Spearman's $p=.1 ; p=.111$. 
higher the score, the higher the risk. Once the risk score had been obtained, a correlation was made with the score obtained on the scale of worry to determine the level of relationship between these two variables, from which Figure 2 was obtained.

Additionally, we were interested in knowing whether sex, education, and occupational demandingness played an important role in the perception of worry. These three aspects were compared, separating for this variable. For the educational attainment comparison, the two educational extremes were considered: Higher education (50) and Postgraduate (38). In order to determine occupational demandingness the occupational index was used with the considerations proposed by Stern et al. (1994) that resulted from a general census. These occupation categories were: 1. Non-professionalized student (elementary, middle, high school); 2. Homemaker; 3. Non-specialized or semi-specialized (non-professional employees); 4. Employees by trade (carpenter craftsmen, merchants or electricians); 5. Employment careers (general employees, clerks or clerics); 6. Advanced job careers (managers, entrepreneurs or high-ranking public servants); 7. Professional or higher university technician. For the purposes of this article and to be able to obtain two comparable groups, the low requirement group (82), belonging to categories 1 to 5 , and the high requirement (173) of categories 6 and 7 were obtained.

\section{DISCUSSION AND CONCLUSION}

The first objective of the study was to determine the prevalence of worry in the Guadalajara population during the COVID-19 quarantine through a convenience sample. It is necessary to clarify the implications of this type of sampling at this point. Among the possible biases is the lack of randomization together with low variability in the population, as a result of which there could be a tendency for only those who felt uncomfortable or worried beforehand answering the questionnaire. However, we observed that there appears to be no significant difference between people who measure the amount of worry they feel and those who do not, which could be considered a solution to this bias. At the same time, caution is required when interpreting the data since it might be difficult to generalize to all social strata in Jalisco, considering that there may be people who do not have contact with the university's social networks or are older adults.

Another possible bias in this type of sampling is the fact that the replicability of the study could pose a problem since the characteristics of time or place of the population would no longer be available if the same population could be used. This would make it partly impossible to undertake with a different population due to the inability to rep- licate the characteristics of the first sample. However, for future studies, attempts are being made to do a retest with a random sampling of the sample to determine whether it has evolved in accordance with the number of days of self-isolation.

According to our results, it was found that $10.6 \%$ of the sample had worry levels at least two standard deviations above the mean, which can be regarded as pathological according to the instruments, while $30.6 \%$ had levels of concern one standard deviation above the mean, classified as high. This means that a total of $40.12 \%$ of the sample could develop some symptoms due to involuntary self-isolation since excess worry is related to generalized anxiety disorder (Padrós-Blázquez et al., 2018).

As for the attitudes, behaviors, and perceptions surrounding the risk of contagion, favorable responses for prevention were observed in most individuals. Answers (Table 3) were tabulated according to frequency and arranged according to the answers on self-isolation. For the primary contact question, it was found that regardless of the length of self-isolation, subjects did not think they had had contact with someone with symptoms, so it is assumed that just over $50 \%$ of the sample had been self-isolated, although they had not recently experienced danger. At least $35 \%$ of people who have self-isolated have adopted proper hygiene measures, together with $29 \%$ of those who have not self-isolated. Regardless of whether they have self-isolated, $32 \%$ doubt they are complying with the hygiene regulations adequately or are not complying with them at all $(2.3 \%)$. As for social relations, the $47 \%$ who did not self-isolate thought that no-one from their nuclear family had had risky contacts, as did $46 \%$ of those who did self-isolate. A total of $1.5 \%$ knew that a relative had symptoms while the remaining $4.7 \%$ were unsure. Regarding extended families, $43 \%$ of those who did not self-isolate reported that they were not infected, followed by $45 \%$ who did self-isolate, who did not report contagion. A total of $8.6 \%$ were unsure whether their extended family had been infected regardless of their self-isolation, while the remaining $2.7 \%$ did know their extended family had been infected.

Regarding social relationships or those not belonging to the family nucleus, the $41 \%$ who did not self-isolate said that members of their closest social circle were not infected, as did the $40 \%$ who self-isolated. Twelve per cent were unsure whether they had been infected and 5.4\% were sure that their close relatives had been infected. For distant (or extended) family relationships, a somewhat different picture emerged. Of those who had self-isolated, 36\% knew someone who had been infected, $4.3 \%$ reported that they did not, and 10.1\% were unsure. At the same time, of those who did not self-isolate, only $3.13 \%$ knew that their extended contacts had been infected, while the remaining $35.6 \%$ thought that none of their extended family members had been infected, while $20.7 \%$ were not unsure, regard- 
less of whether they had self-isolated. Finally, of those who self-isolated, $78 \%$ thought that their actions were important to prevent infection, $12.5 \%$ believed they had no impact, and the remaining $7.4 \%$ were unsure. Of the participants who did not self-isolate, $36 \%$ thought that their actions had an impact against the pandemic, $10.19 \%$ were unsure, and only $3.1 \%$ thought that they did not.

In relation to the risk and worry score (Figure 1), there seems to be a very weak (.1) insignificant association, meaning that it can be assumed that worry is an independent phenomenon from self-isolation for this sample, perhaps due to the fact of its premature launching on March 22 , when the order to self-isolate was issued. On the other hand, this probably indicates that high levels of worry act as as trigger for the predictions of the risk of onset of anxiety, depression, and stress that professionals think could emerge (Unidad de difusión del INPRFM, 2020).

As for groups findings, the following was observed. In the gender comparison, a significant difference was observed. The overlap coefficient indicated that at least $24 \%$ of the observations had different responses. Nevertheless, before assuming that this is an important effect, it should be recalled that the sample is uneven, given that the group comprised almost twice as many women as men. However, one should recall that it has been reported that women tend to score higher than men in terms of worry (Robichaud, Dugas, \& Conway, 2003; Stewart, Taylor, \& Baker, 1997). Perhaps future research, while the pandemic lasts, may change these figures. However, for this sample it was observed that women score higher on the worry indexes by at least six points. A similar thing occurs with occupational demandingness. The group with high occupational demandingness is twice as large as the group with low occupational demands. However, calculating the size of the effect does not predict a scenario that will change regardless of the $n$ since the answers in the two groups only differ by $8 \%$ in this sample.

Regarding educational attainment, although this is a group that can be easily compared due to the number of members, the latter decreased considerably since most of the sample $(66 \%)$ had a university education. Nevertheless, its overlap coefficient does not look promising either in increasing an $n$ since, in the same way as in occupational requirement and isolation, answers only differ by $8 \%$. The comparison that is most reliable both because of its wellmatched number of members and its statistical power is self-isolation, since this apparently did not yield a different effect in the face of the pandemic, although it is important to note that the instrument is out of context, in other words, it does not focus directly on worry about the pandemic but rather about everyday life, so, to a certain extent, it makes it possible to detect a premorbid condition that may become exacerbated as the pandemic progresses due to the harmful effects it has on mental health (Caplan, 2007; Hirsch \& Mathews, 2012; Lauder et al., 2004).
Although we are still at the early stages of the pandemic, it is possible to observe that $40 \%$ of our sample may be vulnerable. Although this vulnerability will depend on psychosocial factors such as overcrowding, the economy, interpersonal relationships, and premorbid status, data suggest that, in a pessimistic scenario, mental health services will be saturated since there is usually not as much demand in natural conditions. At this time, it is crucial for information on the latest findings of the disease to be shared with the public in such a way as to leave little room for uncertainty. It is considered necessary for public health authorities to update their messages to motivate and encourage people to adopt preventive measures more effectively, build trust and avoid misconceptions. If they have adequate access to information, this could significantly prevent people vulnerable to anxiety from developing symptoms.

Appropriate, effective, and rapid information is a means of counteracting the negative psychological effects of quarantine. It is essential for people to understand the situation and to provide them with the necessary supplies. They should be politically encouraged to altruistically choose quarantine to avoid the perception of imposition and restriction of freedom, and to implement preventive mental health measures to cope with future mental disorders. The practice of remotely organized activities could serve as mitigating measures and reduce the likelihood of the psychological costs of COVID-19 quarantine becoming permanent.

\section{Financing}

None.

\section{Conflict of interest}

The authors declare that they have no conflicts of interest.

\section{REFERENCES}

Andersson, L. (1998). Loneliness research and interventions: A review of the literature. Aging \& Mental Health, 2(4), 264-274. doi: 10.1080/13607869856506

Aragonés, J. I., Talayero, F., \& Olivos, P. (2010). Percepción del riesgo de la gripe A (H1N1) desde el "paradigma psicométrico." Revista de Psicología Social, 25(3), 271-282. doi: 10.1174/021347410792675633

Bayés, R., Pastells, S., \& Tuldrá, A. (1995). Percepción de riesgo de transmisión del virus de inmunodeficiencia humana (VIH) en estudiantes universitarios. Cuadernos de Medicina Psicosomática, 33, 22-27. Retrieved from http://www. ub.edu/personal/docencia/infocomp/bayescomp2.htm

Beck, A. T., Epstein, N., Brown, G., \& Steer, R. A. (1988). An inventory for measuring clinical anxiety: Psychometric properties. Journal of Consulting and Clinical Psychology, 56(6), 893-897. doi: 10.1037/0022-006X.56.6.893

Brooks, S. K., Webster, R. K., Smith, L. E., Woodland, L., Wessely, S., Greenberg, N., \& Rubin, G. J. (2020). The psychological impact of quarantine and how to reduce it: rapid review of the evidence. The Lancet, 395(10227), 912-920. doi: 10.1016/S0140-6736(20)30460-8

Bults, M., Beaujean, D. J., de Zwart, O., Kok, G., van Empelen, P., van Steenbergen, J. E., ... Voeten, H. A. (2011). Perceived risk, anxiety, and behavioural responses 
of the general public during the early phase of the Influenza A (H1N1) pandemic in the Netherlands: results of three consecutive online surveys. BMC Public Health, 11(1), 2. doi: 10.1186/1471-2458-11-2

Butler, S. S. (2006). Evaluating the Senior Companion Program. Journal of Gerontological Social Work, 47(1-2), 45-70. doi: 10.1300/J083v47n01_05

Caplan, S. E. (2007). Relations among loneliness, social anxiety, and problematic internet use. CyberPsychology \& Behavior, 10(2), 234-242. doi: 10.1089/ cpb.2006.9963

Cheng, C., \& Cheung, M. W. L. (2005). Psychological responses to outbreak of severe acute respiratory syndrome: A prospective, multiple time-point study. Journal of Personality, 73(1), 261-285. doi: 10.1111/j.1467-6494.2004.00310.x

Davey, G. C. L. (1993). A comparison of three worry questionnaires. Behaviour Research and Therapy, 31(1), 51-56. doi: 10.1016/0005-7967(93)90042-S

Davey, G. C. L. (1994). Pathological worrying as exacerbated problem-solving. In Davey, G. C. L., \& Tallis, F. (Eds.). Worrying: Perspectives on theory, assessment and treatment. Wiley series in clinical psychology, (pp. 35-59). Chichester, England: John Wiley \& Sons. Retrieved from https://psycnet.apa. org/record/1994-97842-002

de Jong, J. C., Claas, E. C. J., Osterhaus, A. D. M. E., Webster, R. G., \& Lim, W. L. (1997). A pandemic warning? Nature, 389(6651), 554. doi: 10.1038/39218

Dong, L., \& Bouey, J. (2020). Public Mental Health Crisis during COVID-19 Pandemic, China. Emerg Infect Dis, 26(7), 1616-1618. doi: 10.3201/eid2607.200407

Fielding, R., Lam, W. W. T., Ho, E. Y. Y., Lam, T. H., Hedley, A. J., \& Leung, G. M. (2005). Avian Influenza Risk Perception, Hong Kong. Emerging Infectious Diseases, 11(5), 677-682. doi: 10.3201/eid1105.041225

Flett, G. L., Goldstein, A. L., Pechenkov, I. G., Nepon, T., \& Wekerle, C. (2016). Antecedents, correlates, and consequences of feeling like you don't matter: Associations with maltreatment, loneliness, social anxiety, and the five-factor model. Personality and Individual Differences, 92, 52-56. doi: 10.1016/j. paid.2015.12.014

Freeston, M. H., Rhéaume, J., Letarte, H., Dugas, M. J., \& Ladouceur, R. (1994). Why do people worry? Personality and Individual Differences, 17(6), 791-802. doi: 10.1016/0191-8869(94)90048-5

Goldsmith, S. K., Pellmar, T. C., Kleinman, A. M., \& Bunney, W. E. (2002). Reducing suicide: A national imperative. Washington, DC: National Academies Press. Retrieved from https://psycnet.apa.org/record/2003-02631-000

González, M., Bethencourt, J. M., Fumero, A., \& Fernández, A. (2006). Spanish adaptation of the "Why worry?" questionnaire. Psicothema, 18(2), 313-318. Retrieved from http://www.ncbi.nlm.nih.gov/pubmed/17296050

González-Olmo, M. J., Ortega-Martínez, A. R., Delgado-Ramos, B., RomeroMaroto, M., \& Carrillo-Diaz, M. (2020). Perceived vulnerability to Coronavirus infection: impact on dental practice. Brazilian Oral Research, 34. doi: 10.1590/1807-3107bor-2020.vol34.0044

Hirsch, C. R., \& Mathews, A. (2012). A cognitive model of pathological worry. Behaviour Research and Therapy, 50(10), 636-646. doi: 10.1016/j. brat.2012.06.007

Jiang, X., Deng, L., Zhu, Y., Ji, H., Tao, L., Liu, L., ... Ji, W. (2020). Psychological crisis intervention during the outbreak period of new coronavirus pneumonia from experience in Shanghai. Psychiatry Research, 286, 112903. doi: 10.1016/j. psychres.2020.112903

Kelly, W. E., \& Miller, M. J. (1999). A Discussion of Worry With Suggestions for Counselors. Counseling and Values, 44(1), 55-66. doi: 10.1002/j.2161007X.1999.tb00152.x

Kuri-Morales, P., Betancourt-Cravioto, M., Velázquez-Monroy, O., Alvarez-Lucas, C., \& Tapia-Conyer, R. (2006). Pandemia de influenza: la respuesta de México. Salud Pública de México, 48(1), 72-79.

Lauder, W., Sharkey, S., \& Mummery, K. (2004). A community survey of loneliness. Journal of Advanced Nursing, 46(1), 88-94. doi: 10.1111/j.13652648.2003.02968.x

Li, H., Liu, S. M., Yu, X. H., Tang, S. L., \& Tang, C. K. (2020). Coronavirus disease 2019 (COVID-19): current status and future perspectives. International Journal of Antimicrobial Agents, 55(5), 105951. doi: 10.1016/j.jiantimicag.2020.105951
Liang, D., Mays, V. M., \& Hwang, W. C. (2017). Integrated mental health services in China: challenges and planning for the future. Health Policy and Planning, 33(1), 107-122. doi: 10.1093/heapol/czx137

Magallares, A., Fuster-Ruiz De Apodaca, M. J., \& Morales, J. F. (2017). Psychometric properties and criterion validity of the Perceived Vulnerability to Disease Scale (PVD) in the Spanish population. Revista de Psicología Social, 32(1), 164-195. doi: 10.1080/02134748.2016.1248025

Maydeu-Olivares, A., \& D'Zurilla, T. J. (1995). A Factor Analysis of the Social Problem-Solving Inventory using Polychoric Correlations. European Journal of Psychological Assessment, 11(2), 98-107. doi: 10.1027/1015-5759.11.2.98

Meyer, T. J., Miller, M. L., Metzger, R. L., \& Borkovec, T. D. (1990). Development and validation of The Penn State Worry Questionnaire. Behaviour Research and Therapy, 28(6), 487-495. doi: 10.1016/0005-7967(90)90135-6

Padrós-Blázquez, F., González-Betanzos, F., Martínez-Medina, M., \& WagnerEcheagaray, F. (2018). Propiedades Psicométricas del Cuestionario de Preocupación Pensilvania (PSWQ) de las Versiones Original y Reducida en Muestras Mexicanas. Actas Españolas de Psiquiatría, 46(4), 117-124. Retrieved from https://dialnet.unirioja.es/servlet/articulo?codigo $=6522850$

Perrin, P. C., McCabe, O. L., Everly, G. S., \& Links, J. M. (2009). Preparing for an Influenza Pandemic: Mental Health Considerations. Prehospital and Disaster Medicine, 24(3), 223-230. doi: 10.1017/S1049023X00006853

R Core Team. (2020). R Foundation for Statistical Computing. (3.6.3). R: A language and environment for statistical computing. https://www.r-project.org/

Robichaud, M., Dugas, M. J., \& Conway, M. (2003). Gender differences in worry and associated cognitive-behavioral variables. Journal of Anxiety Disorders, 17(5), 501-516. doi: 10.1016/S0887-6185(02)00237-2

Ruiz Díaz, M. A., Montorio Cerrato I. M., Nuevo Benítez, R. (2002). Aplicabilidad del Inventario de Preocupación de Pensilvania (PSWQ) a la población de edad avanzada. Ansiedad y Estrés, 8(2-3), 157-172. Retrieved from https://dialnet. unirioja.es/servlet/articulo?codigo $=306804$

Sandín, B., Chorot, P., Valiente, R. M., \& Lostao, L. (2009). Validación española del cuestionario de preocupación PSWQ: estructura factorial y propiedades psicométricas. Revista de Psicopatología y Psicología Clínica, 14(2), 107-122. doi: 10.5944/rppc.vol.14.num.2.2009.4070

Seale, H., Heywood, A. E., McLaws, M. L., Ward, K. F., Lowbridge, C. P., Van, D., \& MacIntyre, C. R. (2010). Why do I need it? I am not at risk! Public perceptions towards the pandemic (H1N1) 2009 vaccine. BMC Infectious Diseases, 10(1), 99. doi: 10.1186/1471-2334-10-99

Shear, M. K., Vander Bilt, J., Rucci, P., Endicott, J., Lydiard, B., Otto, M. W., Pollack, M. H., ... Frank, D. M. (2001). Reliability and validity of a structured interview guide for the Hamilton Anxiety Rating Scale (SIGH-A). Depression and Anxiety, 13(4), 166-178. doi: 10.1002/da.1033

Starcevic, V. (1995). Pathological worry in major depression: a preliminary report. Behaviour Research and Therapy, 33(1), 55-56. doi: 10.1016/0005-7967(93) E0028-4

Stern, Y., Gurland, B., Tatemichi, T. K., Tang, M. X., Wilder, D., \& Mayeux, R. (1994). Influence of education and occupation on the incidence of Alzheimer's Disease. JAMA: The Journal of the American Medical Association, 271(13), 1004-1010. doi: 10.1001/jama.1994.03510370056032

Stewart, S. H., Taylor, S., \& Baker, J. M. (1997). Gender differences in dimensions of anxiety sensitivity. Journal of Anxiety Disorders, 11(2), 179-200. doi: 10.1016/ S0887-6185(97)00005-4

Taha, S., Matheson, K., Cronin, T., \& Anisman, H. (2014). Intolerance of uncertainty, appraisals, coping, and anxiety: The case of the 2009 H1N1 pandemic. British Journal of Health Psychology, 19(3), 592-605. doi: 10.1111/bjhp.12058

Tallis, F., Davey, G., \& Capuzzo, N. (1994). The phenomenology of non-pathological worry: A preliminary investigation. In G. C. L. Davey \& F. Tallis (Eds.), Wiley series in clinical psychology. Worrying: Perspectives on theory, assessment and treatment (p. 61-89). Chichester, England: John Wiley \& Sons. Retrieved from https://psycnet.apa.org/record/1994-97842-003

Taylor, M., Raphael, B., Barr, M., Agho, K., Stevens, G., \& Jorm, L. (2009). Public health measures during an anticipated influenza pandemic: Factors influencing 
willingness to comply. Risk Management and Healthcare Policy, 2, 9-20. doi: 10.2147/RMHP.S4810

Unidad de difusión del INPRFM. (2020). Videoconferencia: Impacto de COVID-19 en la salud mental - March 20. [Youtube]. Retrieved from https://www.youtube. com/watch?v=r8KkRJKAqlA

Velázquez Díaz, M., Espinoza González, F., Martínez Medina, M. P., \& Padrós Blázquez, F. (2016). Pathological worry in hypertensive compared to normotensive population in Michoacan (Mexico). Acta Universitaria, 26(2), 70-76. doi: 10.15174/au.2016.870

Wegner, D. M., \& Zanakos, S. (1994). Chronic Thought Suppression. Journal of Personality, 62(4), 615-640. doi: 10.1111/j.1467-6494.1994.tb00311.x
Wheaton, M. G., Abramowitz, J. S., Berman, N. C., Fabricant, L. E., \& Olatunji, B. O. (2012). Psychological predictors of anxiety in response to the H1N1 (Swine Flu) pandemic. Cognitive Therapy and Research, 36(3), 210-218. doi: 10.1007/ s10608-011-9353-3

Windle, K., Francis, J., \& Coomber, C. (2011). Preventing loneliness and social isolation: interventions and outcomes. London: Social Care Institute for Excellence. Retrieved from https://www.academia.edu/25694243/Preventing loneliness_and_social_isolation_interventions_and_outcomes 